Beata Aleksandra Basińska*, **

Ewa Gruszczyńska**

\title{
Positivity and job burnout in emergency personnel: examining linear and curvilinear relationship
}

\begin{abstract}
The aim of this study was to examine whether the relationship between the ratio of job-related positive to negative emotions (positivity ratio) and job burnout is best described as linear or curvilinear. Participants were 89 police officers (12\% women) and 86 firefighters. The positivity ratio was evaluated using the Job-related Affective Wellbeing Scale (Van Katwyk, Fox, Spector, \& Kelloway, 2000). Exhaustion and disengagement, two components of job burnout, were measured using the Oldenburg Burnout Inventory (Demerouti, Mostert, \& Bakker, 2010). The results of regression analysis revealed that curvilinear relationships between the positivity ratio and two components of job burnout appeared to better fit the data than linear relationships. The relationship between the positivity ratio and exhaustion was curvilinear with a curve point at around 2.1. A similar curvilinear relationship, but with a lower curve point, i.e., around 1.8, was observed for disengagement. It seems that beyond certain values there may be hidden costs of maintaining positive emotions at work. Also, the unequal curve points for subscales suggest that different dimensions of work-related functioning are variously prone to such costs.
\end{abstract}

Key words: job burnout, emotion, positivity, curvilinear relationship, emergency personnel

\section{Introduction}

Affective well-being is often identified within a hedonic framework, based on the assumption that people seek to experience positive states and avoid negative ones (Diener, 2000; Diener, Oishi, \& Lucas, 2003). In line with the broaden and build theory of positive emotions, the affective well-being can be represented by an emotional balance (Fredrickson \& Losada, 2005) which is defined as a ratio of positive to negative emotions. If people feel more positive than negative emotions they have an opportunity to growth and flourish in their life (Fredrickson, 2001; Tugade \& Fredrickson, 2007).

However, it has to be underlined that both negative and positive emotions are crucial for well-being since they play different functions in an adaptation process (Fredrickson \& Branigan, 2005; Lomas \& Ivtzan, 2015). Negative emotions warn against danger and mobilize resources to deal with a threat. Being more pronounced and longer lasting, they restrict attention and narrow behavioural repertoire (Baumeister, Bratslavsky, Finkenauer, \& Vohs, 2001; Clore, 2002; Lewicka, Czapinski, \& Peeters, 1992). In contrast, positive emotions are less diverse and intense. They are salient in situations of less importance for biological survival and as such, they facilitate explorative behaviours and promote new resources (Burns et al., 2008; Cacioppo, Gardner, \& Bernston, 1999; Lewicka et al., 1992; Ouweneel, Le Blanc, Schaufeli, \& van Wijhe, 2012). Additionally, an excess of either positive or negative affective states may be unfavourable for a long-term adaptation (Diener, Colvin, Pavot, \& Allman, 1991).

Nevertheless, the dimension of valence is insufficient for understanding the affective well-being as a whole. Based on the circumplex model of emotions, the dimension of arousal should also be taken into account (Russell, 2003). Hereby, high arousal emotions mobilize personal resources and motivate to action, whereas low

\footnotetext{
* Faculty of Management and Economics, Gdansk University of Technolog

** Faculty of Psychology, SWPS University of Social Sciences and Humanities, Warsaw

Corresponding author: Beata Aleksandra Basińska, e-mail: Beata.Basinska@pg.gda.pl
} 
arousal emotions protect resources and contribute to their reconstruction (Hobfoll, 1989). So far, emotion measurement has been dominated by scales which favours only one, i.e., high, spectrum of arousal (Diener et al., 2009). It might have led to biased conclusions.

Emotions experienced during work change dynamically in a response to a specific context (Weiss \& Cropanzano, 1996). Some aspects of work such as interpersonal relations (e.g. with co-workers, supervisors and clients) as well as organizational factors (salary, job security and respect) are sources of affective reactions (van Katwyk, Fox, Spector, \& Kelloway, 2000). The most frequent approach is to analyse these emotions in terms of positive and negative affective states.

Results of previous studies indicated that valence is more prominent than arousal (Salanova, Del Líbano, Llorens, \& Schaufeli, 2014). However, arousal can be crucial for diagnosis of negative outcomes of job performance (Bakker \& Oerlemans, 2011; Basińska, 2016; Mäkikangas et al., 2015). Thus, only a combination of both dimensions provides a full picture of affective experiences at work, including positive and negative emotions from low to high intensity (Warr, Bindl, Parker, \& Inceoglu, 2014).

Affective well-being can be a proxy of upcoming job burnout. Job burnout is one of the most adverse work consequences caused by individuals' reaction to prolonged occupational stress (Maslach, Schaufeli, \& Leiter, 2001). A new approach to job burnout indicates that two components, exhaustion and disengagement, play a key role in this process (Demerouti, Mostert, \& Bakker, 2010). Exhaustion refers to being physically, cognitively and emotionally drained of energy as a result of exposure to excessive or threatening job demands. Disengagement from work describes an employee's negative attitude toward work content, work objects and work in general (Demerouti, Bakker, Nachreiner, \& Schaufeli 2001). Based on the Job Demands-Resources Theory, burnout is primarily associated with a depletion of energy and personal resources, which makes it a main factor in the health impairment process. Additionally, job burnout may lead to an erosion of work engagement (Bakker, Demerouti, \& Sanz-Vergel, 2014). In general, exhaustion is related to the energy dimension, while disengagement from work is associated with the identification dimension. This broad definition of exhaustion and disengagement is useful for explaining how individuals react to occupational stress within different professions, not just social professions.

So far research has shown that emotions correlate with job burnout and can mediate between job characteristics and prolonged consequences of work for employees. Job burnout is mainly associated with low arousal affective states and a deficiency of high arousal positive affective states (Bakker \& Oerlemans, 2011; Basińska, 2016; Warr et al., 2014). Specifically, job burnout is related to a sense of emptiness (Demerouti et al., 2003), depression (Bianchi, Schonfeld, \& Laurent, 2015), vital exhaustion (Toker, Shirom, Shapira, Berliner, \& Melamed, 2005), fatigue (Basinska \& Wiciak, 2012; Leone, Huibners, Knottnerus, $\&$ Kant, 2008) and anxiety (Cardazo et al., 2012; Peterson,
Demerouti, Bergström, Samuelsson, Åsberg, \& Nygren, 2008). Additionally, if employees experience high arousal unpleasant states, this may amplify aggressive behaviours at work (Balducci et al., 2012). On the other hand, regularly felt fatigue after work means that person experiences low arousal negative emotions which may, in the long term, lead to exhaustion. In contrast, when high arousal positive emotions are rarely present at work, especially in comparison to the whole spectrum of negative emotions, it may result in disengagement from work (Basinska, Wiciak, \& Dåderman, 2014).

Thus, as we have already mentioned, the proportion of positive and negative emotions may be a crucial correlate of well-being at work. The relationship between this proportion and well-being seems to be non-linear with an inflection point at around 3 (Fredrickson \& Losada, 2005). If individuals experience positive emotions more often than negative emotions, they can thrive (Porath, Spreitzer, Gibson, \& Garnett, 2012). Nevertheless, too many positive emotions, when not accompanied by negative emotions, can lead to adverse effects. It means that there is an optimal proportion which promotes positive outcomes and protects against adverse consequences (Fredrickson \& Losada, $2005)$ but above this level desirable results decrease or at most do not increase (Lam, Spreitzer, \& Fritz, 2014; Rego, Sousa, Marques, \& Cunha 2012; Shrira et al., 2011). Hence we focus our attention on the curvilinear effects. However, in spite of Fredickson and Losada claims, there is probably no such value of positive emotion to negative emotion ratio which would be universally optimal (Brown, Sokal, \& Friedman, 2013). For instance, as it was examined more than a decade ago, outcomes of different ratio values may depend on stress level due to a critical life event: relationships are curvilinear and an inflection point is represented by less positive ratio as the stress level is higher (Larsen, Hemenover, Norris, \& Cacioppo, 2003).

Thus, not necessarily the constant " $\pi$-like" value of the ratio but a shape of the relationship seems to be a more fundamental problem (Brown, Sokal, \& Friedman, 2013). Although nonlinear models are potentially widespread in psychology, they have been tested surprisingly rarely in empirical studies (Guastello, 2014). For example Shrira et al. (2011) have shown the quadratic relationship of positivity ratio with regard to traumatic distress among hospital personnel exposed to war-related stress. Rego et al. (2012) have revealed that the relationship between positivity ratio and creativity is curvilinear, in such a way that excessive positivity is detrimental to creativity at work. However, more research of this kind is needed in the work context.

\section{Aim and hypotheses}

Thus, the question arises if optimal proportion of positive to negative emotions can be captured in a work context and - consequently - whether too high positivity may be harmful? It is, in fact, a question about the shape of this relationship. Many researchers have tested a linear relationship between emotions and different work outcomes. However, too rarely has this relationship been 
compared to a non-linear one. The aim of this study is to examine which function of ratio of job-related positive to negative emotions, curvilinear or linear, better describes its relationship with job burnout. Specifically, we want to verify whether a quadratic function adds above and beyond what a linear one can explain in terms of job burnout variance.

The relationship between emotions (as a positivity ratio) and job burnout will be examined in a group of emergency personnel. Usually, employees experience more positive and less intense emotions (Balducci, Cecchin, Fraccaroli, \& Schaufeli, 2012; Machin \& Hoare, 2008; van Katwyk et al., 2000). However, police officers and firefighters may feel intense emotions more often than other professions due to a specific character of their duties (Basińska, 2013; Ogińska-Bulik \& Juczyński, 2016). Thus, it is important to verify whether this theoretically sound curvilinear relationship will be observed in jobs of special psychological demands. Thus, we hypothesize that in an emergency personnel:

Hypothesis 1. A quadratic function would describe the relationship between the positivity ratio and exhaustion better than a linear function.

Hypothesis 2. A quadratic function would describe the relationship between the positivity ratio and disengagement better than a linear function.

\section{Methods}

\section{Participants and procedure}

A cross-sectional study was conducted in a specific group of emergency personnel. A convenience sample comprising 175 employees was collected. This group consisted of 86 firefighters and 89 police officers. All the firefighters were men. Women accounted for $12 \%$ of police officers. This gender ratio is similar to the ratio for Polish police officers where women account for 14\% (Basińska \& Wiciak, 2015). Thirty three percent of the participants have a higher education (i.e., at least 17 years of schooling, 69\% were married or in a stable relationship).

Participation in the study was voluntary and anonymous. Due to a significant amount of systematically missing data, the protocols of seven participants were excluded from further analyses. Thus, the final sample consisted of 168 participants, which represented $96 \%$ of the initial sample size.

\section{Instruments}

The ratio of positive to negative emotions at work, including various states of arousal, was evaluated using the Job-Related Affective Well-Being Scale - shortened version (Van Katwyk et al., 2000; Polish version by Basinska, Gruszczynska, \& Schaufeli, 2014). This scale consists of 20 adjectives which describe affective states experienced during work. It measures four categories of emotions: high arousal positive emotions (HPHA 5 items, e.g. enthusiastic, inspired) and low arousal positive emotions (HPLA 5 items, e.g. calm, relaxed) as well as high arousal negative emotions (LPHA 5 items, e.g. angry, furious) and low arousal negative emotions (LPLA 5 items, e.g. bored, fatigued). The format of the answer serves to assess the frequency of these emotional reactions during the past month. Every item is assessed on a 5-point scale, from 1 - "never" to 5 - "extremely often". Higher scores indicate more positive or more negative affective well-being at work for both, low and high arousal. In our study, Cronbach's alpha coefficient was .78 and .76 for high and low arousal positive emotions and .75 and .73 for high and low arousal negative emotions. The positivity ratio was calculated by dividing the sum of high and low arousal positive emotions score by the sum of high and low arousal negative emotions score. The equation is presented as follows:

$$
\text { Positivity }=\frac{H P H A+H P L A}{L P H A+L P L A}
$$

Note. HPHA - high arousal positive emotions; HPLA - low arousal positive emotions; LPHA - high arousal negative emotions; LPLA - low arousal negative emotions.

Exhaustion and disengagement, two components of job burnout, were measured using the Oldenburg Burnout Inventory (Demerouti, Mostert, \& Bakker, 2010; Polish version by Baka \& Basinska, 2016). Exhaustion is examined using 8 items which are negatively and positively formulated (i.e. "During my work, I often feel emotionally drained" or "I can tolerate the pressure of my work very well"). Disengagement is assessed using 8 items which are also reframed negatively and positively (i.e. "Over time, one can become disconnected from this type of work" or "I always find new and interesting aspects in my work"). Every item is scored on a 4-point scale ranging from 1 - "agree" to 4 - "disagree". Negatively framed items are inversely coded. Higher scores indicate a higher level of exhaustion and a higher level of disengagement. The Cronbach's alpha coefficient in our study was .82 for exhaustion and .74 for disengagement.

\section{Data analysis}

The descriptive statistics and $r$-Pearson correlations were calculated using IBM SPSS Statistics Version 24. Then the regression assumptions were tested, i.e., existence of outliners, collinearity and heteroscedasticity (Tabachnik, \& Fidell, 2013). Further hierarchical regressions were conducted, for exhaustion and disengagement separately. Each time in the first step burnout was regressed on the sociodemographic data to be controlled for, then a linear term of the positivity ratio was entered, and finally in the third step a squared positivity ratio term was added. In order to reduce multicollinearity, the positivity ratio was centred before being squared. Two conditions are necessary to observe curvilinear relationships of a convex shape assumed in the hypotheses. First, the coefficient for the linear term of the positivity ratio should be significant and negative. Second, the coefficient for the quadratic term of the positivity ratio should also be significant, but positive. The optimal positivity ratio level was defined as an inflection point of the quadratic function. It was 
calculated according to Cohen, Cohen, West and Aiken's (2003) formula, that negative value of the unstandardized coefficient for the linear term was divided by the doubled unstandardized coefficient for the quadratic term. To describe effect size for the increase in variance explained by the quadratic model as compared to the linear one, Cohen's $f^{2}$ coefficient was computed (Cohen et al., 2003). The equation is presented as follows:

$$
f^{2}=\frac{R_{Q}^{2}-R_{L}^{2}}{1-R_{Q}^{2}}
$$

Note. $f^{2}=$ Cohen's coefficient; $R_{Q}^{2}=$ percent of variance in dependent variable explained in quadratic model; $R_{L}^{2}=$ percent of variance in dependent variable explained in linear model.

Values of Cohen's $f^{2}$ coefficient around $.02, .15$ and .35 indicate small, medium and large effect size respectively.

\section{Results}

\section{Descriptive statistics}

The descriptive statistics as well as the correlations between the variables under study are presented in Table 1.

As it can be seen, almost $70 \%$ of the studied emergency personnel reported experiencing positivity in a work setting: as a reaction to any part of their job (e.g., tasks, co-workers, supervisor, clients, pay) the frequency of positive emotions was higher than that of negative ones (range from 0.49 to 3.70 ). The difference between mean level of exhaustion and disengagement was significant in the study group $(t=-2.41, d f=167, p=.017)$.

Also, four groups of emotions were moderately related to exhaustion and disengagement in a similar way.
A slightly different pattern of relationship between high arousal emotions and exhaustion was observed: stronger for negative than for positive emotions. Further, the positivity ratio and the squared positivity ratio were moderately correlated with two components of burnout.

For all the variables values of skewness and kurtosis were between -2 and +2 which is considered acceptable range for a normal distribution (Gravetter \& Wallnau, 2014). The Grubb's test (GraphPad Software Inc., 2016; Grubbs, 1969) showed no outliers expect for one case for squared centered positivity ratio. The analyses were re-run with and without this case and as its removal did not change the results it was kept in the final database. Also, the examination of residuals scatterplots did not indicate any serious violation of normality and homoscedasticity assumptions (Tabachnik \& Fidell, 2013). Finally, variance inflation factor below 2 for each analysis suggests no multicollinearity problem.

Missing data were observed only for sociodemographic variables and ranged from $0.01 \%$ (sex) to $3.5 \%$ (education); Litlle's test showed that they were missing completely at random (MCAR, Graham, 2009); $\left.\chi^{2}(4, \mathrm{~N}=168)=8.28, p=0.08\right)$, thus according to contemporary recommendations EM algorithm was used to replace them instead of pairwise or listwise deletion.

\section{Quadratic versus linear regression models}

Linear and curvilinear relationships between the positivity ratio and the components of burnout were examined using a series of hierarchical regressions. Exhaustion was regressed onto sociodemographic variables in step 1 , and then onto the linear positivity ratio term and the quadratic positivity ratio term in step 2 and 3, respectively. The results showed that the quadratic relationship explains exhaustion variance of around $4 \%$ better than the linear relationship does (adjusted $R^{2}$ increase

Table 1. Descriptive statistics and Pearson's $r$ correlations $(N=168)$

\begin{tabular}{|c|c|c|c|c|c|c|c|c|c|c|c|c|}
\hline \multirow{2}{*}{ Variable } & \multirow{2}{*}{$M$} & \multirow{2}{*}{$S D$} & \multirow{2}{*}{ Skewness } & \multirow{2}{*}{ Kurtosis } & \multirow{2}{*}{ Range } & \multicolumn{7}{|c|}{ Pearson's r correlations } \\
\hline & & & & & & 1 & 2 & 3 & 4 & 5 & 6 & 7 \\
\hline 1. HPHA & 14.74 & 3.52 & 0.16 & -0.37 & $7-24$ & & & & & & & \\
\hline 2. HPLA & 15.17 & 3.29 & 0.36 & -0.45 & $9-25$ & .74 & & & & & & \\
\hline 3. LPHA & 11.72 & 3.39 & 0.27 & 0.10 & $5-23$ & -.33 & -.55 & & & & & \\
\hline 4. LPLA & 11.59 & 3.41 & 0.67 & 0.26 & $5-21$ & -.33 & -.48 & .69 & & & & \\
\hline 5. Positivity ratio & 1.43 & 0.65 & 1.31 & 1.96 & $0.49-3.70$ & .67 & .78 & -.80 & -.74 & & & \\
\hline 6. Positivity ratio squared & 2.45 & 2.46 & 2.49 & 7.07 & $0.24-13.69$ & .60 & .69 & -.72 & -.64 & .97 & & \\
\hline 7. Exhaustion & 16.85 & 4.54 & -0.07 & -0.27 & $8-28$ & -.45 & -.59 & .56 & .59 & -.68 & -.61 & \\
\hline 8. Disengagement & 17.33 & 3.93 & -0.12 & 0.53 & $8-27$ & -.48 & -.56 & .49 & .59 & -.63 & -.56 & .82 \\
\hline
\end{tabular}

Note. HPHA - high arousal positive emotions; HPLA - low arousal positive emotions; LPHA - high arousal negative emotions; LPLA - low arousal negative emotions.

All the correlations are significant at $p<.05$ (after Bonferroni correction .05/28). Descriptive statistics for positivity ratio and positivity ratio squared calculated before centering. 
from .46 to .49), after control for sociodemographic data. However, the effect size was small $\left(f^{2}=.06\right)$. Both conditions for assumed curvilinear relationship between the positivity ratio and exhaustion were fulfilled. The linear parameter of the positivity ratio was significant and negative in contrast to the quadratic parameter of the positivity ratio, which was significant and positive (see Table 2). The optimum positivity ratio score was 2.07 $[-(-5.97) /(2 \times 1.44)]$. In other words, a higher positivity ratio is related to lower exhaustion until an inflection point of 2.07, after which the relationship is reversed, i.e., a higher positivity ratio is related to higher exhaustion. Figure 1 presents this U-shape relationship between the positivity ratio and exhaustion. Therefore, hypothesis 1 was supported.

Further, the same pattern of hierarchical regression was applied to disengagement as a dependent variable. Again, the quadratic relationship better explains disengagement variance of about $4 \%$ than the linear relationship does (adjusted $R^{2}$ increase from .45 to .49 ) but again the effect size is small $\left(f^{2}=.06\right)$. The pattern of the relationship was repeated, that is, the coefficient for the linear term was significant and negative whereas for the quadratic term it was significant but positive (see Table 3). The inflection point was $1.80[-(-4.75) /(2 \times 1.32)]$. The U-shape relationship between the positivity ratio and exhaustion is presented in Figure 2. As can be seen, higher values of the positivity ratio are related to lower values of engagement, but after a positivity ratio value of 1.80 is exceeded, this trend becomes reversed. Therefore, hypothesis 2 was also confirmed.

Additionally, it is worth noticing that sociodemographic variables accounted only for around 4\%
Figure 1. Quadratic relationship between positivity ratio and exhaustion

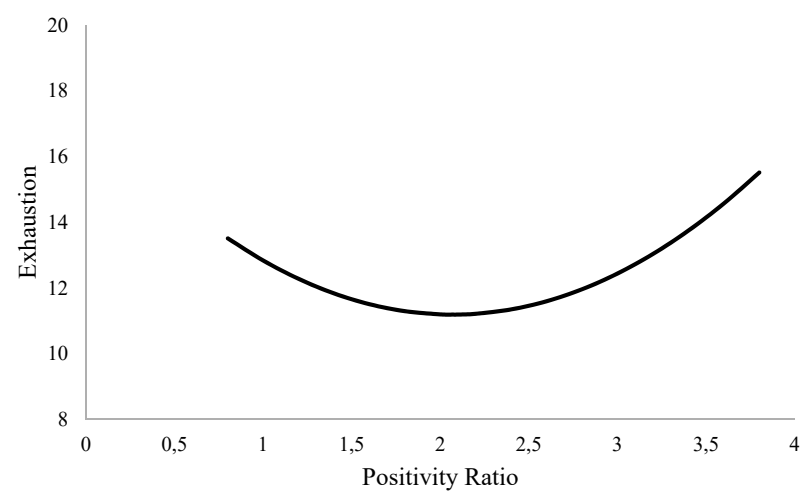

of explained variance in exhaustion but for $12 \%$ in disengagement, specifically due to a protective role of having a higher education.

Finally, as the curvilinear effect may be modified by a subgroup of emergency personnel, i.e., present only in one of them, a moderation analyses was done to rule out this possibility. No significant interactional effects were obtained (for exhaustion $\beta=-.11, p=.12$; for disengagement $\beta=.08, p=.27$ ).

\section{Discussion}

The findings of the study revealed that a U-shape relationship between the ratio of positive and negative emotions and two components of job burnout is better fitted to the data than a linear one. We observed a curvilinear relationship for exhaustion, i.e., a higher positivity ratio

Table 2. Model summary of hierarchical quadratic regression of exhaustion on positivity ratio (standardized regression coefficients)

\begin{tabular}{lccc}
\hline \multicolumn{1}{c}{ Variables } & Step 1 & Step 2 & Step 3 \\
\hline Sociodemographic variables & & & -.006 \\
\hline Sex $(0=$ women, $1=$ men $)$ & -.127 & -.053 & -.038 \\
\hline Education $(0=$ secondary, $1=$ higher $)$ & $-.193^{*}$ & -.058 & $-.124^{*}$ \\
\hline Being in relationship $(0=$ no, $1=$ yes $)$ & -.102 & $-.122^{*}$ & $-.844^{* * *}$ \\
\hline Linear & & $-.661 * * *$ & $.260^{* * *}$ \\
\hline Positivity ratio & & & \\
\hline Quadratic & & & $.51 / .49$ \\
\hline Positivity ratio squared & & $.47 / .46$ & $32.11^{* * *}$ \\
\hline Model summary & $.06 / .04$ & $35.11^{* * *}$ & $12.06^{* * *}$ \\
\hline$R^{2} /$ adjusted $R^{2}$ & $3.47^{* *}$ & $121.00^{* * *}$ & \\
\hline F for model & & & \\
\hline F for $R^{2}$ change
\end{tabular}

Note. ${ }^{*} p<.05 ; * * p<.01 ; * * * p \leq .001$ 
Table 3. Model summary of hierarchical quadratic regression of disengagement on positivity ratio (standardized regression coefficients)

\begin{tabular}{|c|c|c|c|}
\hline Variables & Step 1 & Step 2 & Step 3 \\
\hline \multicolumn{4}{|l|}{ Sociodemographic variables } \\
\hline $\operatorname{Sex}(0=$ women, $1=$ men $)$ & $-.163 *$ & -.098 & -.048 \\
\hline Education $(0=$ secondary, $1=$ higher $)$ & $-.322 * * *$ & $-.202 * * *$ & $-.180 * *$ \\
\hline Being in relationship $(0=$ no, $1=$ yes $)$ & -.081 & -.099 & $-.124 *$ \\
\hline \multicolumn{4}{|l|}{ Linear } \\
\hline Positivity ratio & & $-.587 * * *$ & $-.783 * * *$ \\
\hline \multicolumn{4}{|l|}{ Quadratic } \\
\hline Positivity ratio squared & & & $.278^{* * *}$ \\
\hline \multicolumn{4}{|l|}{ Model summary } \\
\hline$R^{2} /$ adjusted $R^{2}$ & $.14 / .12$ & $.46 / .45$ & $.50 / .49$ \\
\hline F for model & $8.30 * *$ & $33.43 * * *$ & $31.20 * * *$ \\
\hline F for $R^{2}$ change & & $94.08 * * *$ & $12.46^{* * *}$ \\
\hline
\end{tabular}

Note. $* p<.05 ; * * p<.01 ; * * * p \leq .001$

Figure 2. Quadratic relationship between positivity ratio and disengagement

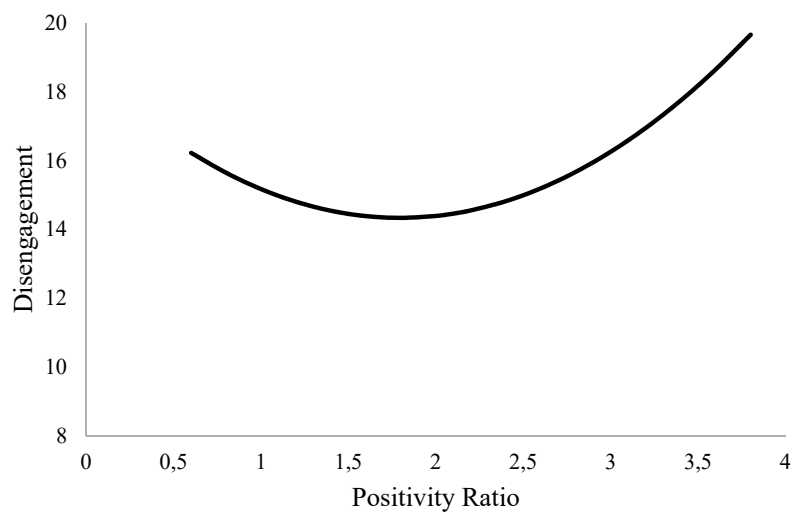

after exceeding a value slightly above 2.0 was associated with higher exhaustion. Further, we also observed an analogous curvilinear relationship for disengagement with a vertex above 1.8 , after which a higher positivity ratio was associated with higher disengagement. Although the trends for both components of job burnout appeared to be similar, the inflection point of the positivity ratio was lower for disengagement than for exhaustion.

Thus, our findings suggest that there may be an optimal value of the ratio between positive and negative emotions in a work context, although in accordance with a current criticism it is no universal and the effect is rather weak (Brown, Sokal, \& Friedman, 2013). Positivity is probably adaptive only to a certain point when dealing with externally and obligatory defined demands, which is typical for work settings. Thus, at least as far as exhaustion and disengagement are concerned, its beneficial effect may turn into a potentially disadvantageous one. Shrira et al. (2010) presented similar results regarding work in stressful conditions. A very high positivity ratio may not have an added protective value and may, in fact, lead to potential costs which can result in depleted energy and personal resources as well as disengagement among employees.

Therefore, although positive emotions are necessary for well-being, there may be hidden costs of maintaining positive emotions at work, especially if these positive emotions are too high (Diener, Colvin, Pavot, \& Allman, 1991) and if they are experienced by employees who are already experiencing significant and chronic depletion of personal resources (Hobfoll, 2002). This suggests that the complex interplay between affective states is adaptive for functioning in a work context. If employees are aware that certain aspects of their work contribute to their negative emotions, they can implement self-protective behaviours, adjusting for circumstances (Fredrickson, 2001). In such a light, a deficiency of negative emotions, or denying them, may be more costly to health than a similar deficiency of positive affective states. This is consistent with the results of Rego et al. (2012) that a higher positivity ratio, if accompanied by a very low level of negative emotions, may harm creativity, despite the fact that, according to empirical findings, positive emotions are crucial for boosting creativity (Parke, Seo, \& Sherf, 2015).

Hence, some practical implications derive from this study. Human resources practices and management standards should take into account the costs of extreme emotions, not only negative ones, but also positive. This is usually omitted - or even worse - when 'keeping a smiling 
face' is treated as an organizational norm and only positive emotions are accepted and reinforced regardless of the circumstances. The nature of the work of emergency personnel, because of their exposure to stressful events, includes intense emotions of both valence so this issue should be addressed in burnout prevention at organizational and individual level.

However, the study has some shortcomings. First, the sample is a small group of emergency personnel with the majority of participants being male. Even if such overrepresentation is justified by the nature of this profession, it must be underlined that the results may be gender biased. Also, the findings need to be confirmed in other professional groups. Second, we used a crosssectional design, thus any implications regarding causality are restricted. The theoretical framework assumes that affective well-being precedes job burnout. Nonetheless, a longitudinal design is necessary to verify this relationship, including both the above-mentioned non-linearity and control of a baseline job burnout level. Additionally, curvilinear relationships other than quadratic ones should be examined. It is likely, for instance, that after reaching an inflection point the trend does not reverse, but reaches a plateau. Finally, the ratio of positive to negative emotions as an indicator of emotional balance has some shortcomings (Cortina, 1993; Kim \& Mueller, 2001). Some authors propose alternative indicators, e.g., a difference between positive and negative emotions or ratio of positive emotions to sum of positive and negative emotions (Brown et al., 2014; Guastello, 2014). Still they are not free from their own limitations. To sum up, our decision was based on the theoretical assumption (Fredrickson, 2001; Fredrickson \& Losada, 2005) and methodology used in the previous studies (Rego et al., 2012; Shrira et al., 2011) for comparison purposes.

Despite these limitations, our study enhanced the knowledge about affective well-being understood as a state rather than as a stable disposition and defined as a ratio between positive and negative emotions. Also, its relationship with job burnout suggests that such well-being, even if it seems to be positive, may have prolonged and adverse consequences on functioning in a work context. To conclude, the positivity ratio may have a curvilinear relationship with negative work outcomes among emergency personnel which should be taken into account when burnout prevention is to be implemented.

\section{References}

Baka, L., \& Basinska, B.A. (2016). Psychometryczne właściwości polskiej wersji Oldenburskiego Kwestionariusza Wypalenia Zawodowego (OLBI) [Psychometric properties of the polish version of the Oldenburg Burnout Inventory]. Medycyna Pracy, 67(1), 29-41. doi: 10.13075/mp.5893.00353.

Bakker, A.B., Demerouti, E., \& Sanz-Vergel, A.I. (2014). Burnout and work engagement: The JD-R approach. Annual Review of Organizational Psychology and Organizational Behavior, 1(1), 389-411.

Bakker, A.B., \& Oerlemans, W. (2011). Subjective well-being in organizations. In K. Cameron, \& G. Spreitzer (Eds.), The Oxford handbook of positive organizational scholarship (pp. 178-189). Oxford: Oxford University Press.
Balducci, C., Cecchin, M., Fraccaroli, F., \& Schaufeli, W.B. (2012). Exploring the relationship between workaholism and workplace aggressive behaviour: The role of job-related emotion. Personality and Individual Differences, 53(5), 629-634.

Basinska, B., Gruszczynska, E., \& Schaufeli, W. (2014). Psychometric properties of the polish version of the Job-related Affective Wellbeing Scale. International Journal of Occupational Medicine and Environmental Health, 27(6), 993-1004.

Basińska, B.A. (2016). Emocje w pracy: rozszerzenie teorii Wymagania - Zasoby w Pracy. Gdańsk: Wydawnictwo Politechniki Gdańskiej.

Basińska, B.A. (2013). Emocje w miejscu pracy w zawodach podwyższonego ryzyka psychospołecznego. Polskie Forum Psychologiczne, 18(1), 81-92.

Basinska, B.A., \& Wiciak, I. (2015). Kobiety w wydziałach logistyki Policji. Zeszyty Naukowe Uniwersytetu Szczecińskiego. Problemy Zarządzania, Finansów i Marketingu, 41(1), 223-236.

Basinska, B.A., \& Wiciak, I. (2012). Fatigue and professional burnout in police officers and firefighters. Internal Security, 4(2), 267-275.

Basinska, B.A., Wiciak, I., \& Maria Dåderman, A. (2014). Fatigue and burnout in police officers: the mediating role of emotions. Policing: An International Journal of Police Strategies \& Management, 37(3), 665-680.

Baumeister, R.F., Bratslavsky, E., Finkenauer, C., \& Vohs, K.D. (2001) $\mathrm{Bad}$ is stronger than good. Review of General Psychology, 5(4), 323-370. doi: http://dx.doi.org/10.1037/1089-2680.5.4.323

Bianchi, R., Schonfeld, I.S., \& Laurent, E. (2015). Burnout-depression overlap: A review. Clinical Psychology Review, 36, 28-41. doi: http://dx.doi.org/10.1016/j.cpr.2015.01.004

Brown, N.J.L., Sokal, A.D., \& Friedman, H.L. (2014). The persistence of wishful thinking. American Psychologist, 69(6), 629-632. doi: http://dx.doi.org/10.1037/a0037050

Brown, N.J., Sokal, A.D., \& Friedman, H.L. (2013). The complex dynamics of wishful thinking: The critical positivity ratio. American Psychologist, 68(9), 801-813.

Burns, A.B., Brown, J.S., Sachs-Ericsson, N., Plant, E.A., Curtis, J.T., Fredrickson, B.L., \& Joiner, T.E. (2008). Upward spirals of positive emotion and coping: Replication, extension, and initial exploration of neurochemical substrates. Personality and Individual Differences, 44(2), 360-370. doi: http://dx.doi.org/10.1016/j. paid.2007.08.015

Cacioppo, J.T., Gardner, W.L., \& Berntson, G.G. (1999). The affect system has parallel and integrative processing components: Form follows function. Journal of Personality and Social Psychology, 76(5), 839-855.

Cardozo, B.L., Crawford, C.G., Eriksson, C., Zhu, J., Sabin, M., Ager, A., \& Simon, W. (2012). Psychological distress, depression, anxiety, and burnout among international humanitarian aid workers: A longitudinal study. PLoS one, 7(9), e44948.

Clore, G.C. (2002). Dlaczego przezywamy emocje. In P. Ekman, J.R. Davidson (Eds.). Natura emocji. Podstawowe zagadnienia (pp. 94-102). Gdańsk: GWP

Cohen, J., Cohen, P., West, S.G., \& Aiken, L.S. (2003). Applied multiple regression/correlation analysis for the behavioral sciences (3rd ed.). Mahwah NJ: Lawrence Erlbaum Associates Inc.

Cortina, J.M. (1993). Interaction, nonlinearity, and multicollinearity: Implications for multiple regression. Journal of Management, 19(4), 915-922.

Demerouti, E., Bakker, A.B., Nachreiner, F., \& Schaufeli, W.B. (2001). The job demands-resources model of burnout. Journal of Applied Psychology, 86(3), 499-512.

Demerouti, E., Mostert, K., \& Bakker, A.B. (2010). Burnout and work engagement: a thorough investigation of the independency of both constructs. Journal of Occupational Health Psychology, 15(3), 209-222.

Diener, E. (2000). Subjective well-being: The science of happiness and a proposal for a national index. American Psychologist, 55(1), 34-43. doi: http://dx.doi.org/10.1037/0003-066X.55.1.34.

Diener, E., Colvin, C.R., Pavot, W.G., \& Allman, A. (1991). The psychic costs of intense positive affect. Journal of personality and social psychology, 61(3), 492-503. doi: http://dx.doi.org/10.1037/00223514.61.3.492 
Diener, E., Colvin, C.R., Pavot, W.G., \& Allman, A. (1991). The psychic costs of intense positive affect. Journal of Personality and Social Psychology, 61(3), 492-503.

Diener, E., Oishi, S., \& Lucas, R.E. (2003). Personality, culture, and subjective well-being: Emotional and cognitive evaluations of life. $A n-$ nual Review of Psychology, 54(1), 403-425.

Diener, E., Wirtz, D., Biswas-Diener, R., Tov, W., Kim-Prieto, C. Choi, D.W., \& Oishi, S. (2009). New measures of well-being. In E. Diner (Ed.), Assessing well-being (pp. 247-266). Springer Netherlands.

Fredrickson, B.L. (2001). The role of positive emotions in positive psychology: The broaden-and-build theory of positive emotions. American Psychologist, 56(3), 218-226.

Fredrickson, B.L., \& Branigan, C. (2005). Positive emotions broaden the scope of attention and thought-action repertoires. Cognition and Emotion, 19(3), 313-332. doi: http://dx.doi.org/10.1080/0269 9930441000238

Fredrickson, B.L., \& Losada, M.F. (2005). Positive affect and the complex dynamics of human flourishing. American Psychologist, 60(7), 678-686.

Graham, J.W. (2009). Missing data analysis: Making it work in the rea world. Annual Review of Psychology, 60, 549-576.

GraphPad Software Inc. (2016). Scientific Software. QuickCalcs. Available at https://graphpad.com/quickcalcs/grubbs1/ [5th December 2016].

Gravetter, F.J., \& Wallnau, L.B. (2014). Essentials of Statistics for the Behavioral Sciences $\left(8^{\text {th }}\right.$ ed.). Wadsworth: Cengage Learning.

Grubbs, F.E. (1969). Procedures for detecting outlying observations in samples. Technometrics, 11, 1-21.

Guastello, S.J. (2014). Nonlinear dynamical models in psychology are widespread and testable. American Psychologist, 69(6), 628-629.

Hobfoll, S.E. (2002). Social and psychological resources and adaptation. Review of General Psychology, 6(4), 307-324.

Hobfoll, S.E. (1989). Conservation of resources: A new attempt at conceptualizing stress. American Psychologist, 44(3), 513-524.

Kim, K.A., \& Mueller, D.J. (2001). To balance or not to balance: Confirmatory factor analysis of the affect-balance scale. Journal of Happiness Studies, 2(3), 289-306. doi: http://dx.doi.org/10.1023/ A:1013519931082

Lam, C.F., Spreitzer, G., \& Fritz, C. (2014). Too much of a good thing: Curvilinear effect of positive affect on proactive behaviors. Journal of Organizational Behavior, 35(4), 530-546.

Larsen, J.T., Hemenover, S.H., Norris, C.J., \& Cacioppo, J.T. (2003). Turning adversity to advantage: On the virtues of the coactivation of positive and negative emotions. In L.G. Aspinwall, \& U.M. Staudinger (Eds.), A psychology of human strengths: Fundamental questions and future directions for a positive psychology (pp. 211-225). Washington, DC: American Psychological Association.

Leone, S.S., Huibers, M.J.H., Knottnerus, J.A., \& Kant, I.J. (2008). A comparison of the course of burnout and prolonged fatigue: A 4-year prospective cohort study. Journal of Psychosomatic Research, 65(1), 31-38. doi: http://dx.doi.org/10.1016/j.jpsychores.2008.03.018

Lewicka, M., Czapinski, J., \& Peeters, G. (1992). Positive-negative asymmetry or "When the heart needs a reason". European Journal of Social Psychology, 22(5), 425-434. doi: http://dx.doi.org/10.1002 ejsp. 2420220502

Lomas, T., \& Ivtzan, I. (2015). Second wave positive psychology: exploring the positive-negative dialectics of wellbeing. Journal of Happiness Studies, 1-16. doi: http://dx.doi.org/10.1007/s10902-015$9668-\mathrm{y}$
Machin, M.A., \& Hoare, P.N. (2008). The role of workload and driver coping styles in predicting bus drivers' need for recovery, positive and negative affect, and physical symptoms. Anxiety, Stress \& Coping: An International Journal, 21(4), 359-375. doi: http://dx.doi. org/10.1080/10615800701766049

Mäkikangas, A., Rantanen, J., Bakker, A.B., Kinnunen, M.L., Pulkkinen, L., \& Kokko, K. (2015). The Circumplex Model of Occupational Well-being: Its Relation with Personality. Journal for PersonOriented Research, 1(3), 115-129. doi: 10.17505/jpor.2015.13

Maslach, C., Schaufeli, W.B., \& Leiter, M.P. (2001). Job burnout. Annual Review of Psychology, 52(1), 397-422.

Ogińska-Bulik, N., \& Juczyński, Z. (2016). Ruminacje jako wyznaczniki negatywnych i pozytywnych konsekwencji doświadczonych zdarzeń traumatycznych u ratowników medycznych. Medycyna Pracy, 67(2), 201-211.

Ouweneel, E., Le Blanc, P.M., Schaufeli, W.B., \& van Wijhe, C.I. (2012). Good morning, good day: A diary study on positive emotions, hope, and work engagement. Human Relations, 65(9), 1129-1154.

Parke, M.R., Seo, M., \& Sherf, E.N. (2015). Regulating and facilitating: The role of emotional intelligence in maintaining and using positive affect for creativity. Journal of Applied Psychology, 100(3), 917-934.

Peterson, U., Demerouti, E., Bergström, G., Samuelsson, M., Åsberg, M., $\&$ Nygren, Å. (2008). Burnout and physical and mental health among Swedish healthcare workers. Journal of Advanced Nursing, 62(1), 84-95. doi: http://dx.doi.org/10.1111/j.1365-2648.2007.04580.x

Porath, C., Spreitzer, G., Gibson, C., \& Garnett, F.G. (2012). Thriving at work: Toward its measurement, construct validation, and theoretical refinement. Journal of Organizational Behavior, 33(2), 250-275.

Rego, A., Sousa, F., Marques, C., \& Cunha, M.P.E. (2012). Optimism predicting employees' creativity: The mediating role of positive affect and the positivity ratio. European Journal of Work and Organizational Psychology, 21(2), 244-270.

Russell, J.A. (2003). Core affect and the psychological construction of emotion. Psychological Review, 110(1), 145-172.

Shrira, A., Palgi, Y., Wolf, J.J., Haber, Y., Goldray, O., Shacham-Shmueli, E., \& Ben-Ezra, M. (2011). The positivity ratio and functioning under stress. Stress and Health, 27(4), 265-271.

Tabachnick, B.G., \& Fidell, L.S. (2013). Using Multivariate Statistics (6th ed.). New Jersey: Pearson Education Inc.

Toker, S., Shirom, A., Shapira, I., Berliner, S., \& Melamed, S. (2005). The association between burnout, depression, anxiety, and inflammation biomarkers: C-reactive protein and fibrinogen in men and women. Journal of Occupational Health Psychology, 10(4), 344-362. doi: http://dx.doi.org/10.1037/1076-8998.10.4.344

Tugade, M.M., \& Fredrickson, B.L. (2007). Regulation of positive emotions: Emotion regulation strategies that promote resilience. Journal of Happiness Studies, 8(3), 311-333. doi: http://dx.doi.org/10.1007/ s10902-006-9015-4

Van Katwyk, P.T., Fox, S., Spector, P.E., \& Kelloway, E.K. (2000). Using the Job-Related Affective Well-Being Scale (JAWS) to investigate affective responses to work stressors. Journal of Occupational Health Psychology, 5(2), 219-230.

Warr, P., Bindl, U.K., Parker, S.K., \& Inceoglu, I. (2014). Four-quadrant investigation of job-related affects and behaviours. European Journal of Work and Organizational Psychology, 23(3), 342-363.

Weiss, H.M., \& Cropanzano, R. (1996). Affective events theory: A theoretical discussion of the structure, causes and consequences of affective experiences at work. In B.M. Staw, \& L.L. Cummings (Eds.). Research in organizational behavior: An annual series of analytical essays and critical reviews, Vol. 18 (pp. 1-74). US: Elsevier Science/JAI Press.

\section{ACKNOWLEDGMENT}

We acknowledge the financial support of the National Science Centre of Poland within the research "Exploration of new aspects of Job Demands - Resources theory: a diary study of affect, coping and occupational well-being" No. UMO-2015/17/B/HS6/04178. 